\title{
Dicalcium Phosphate Crystals Measurement
}

National Cancer Institute

\section{Source}

National Cancer Institute. Dicalcium Phosphate Crystals Measurement. NCI Thesaurus.

Code C135407.

The determination of the amount of dicalcium phosphate crystals in a biological sample. 